\title{
Structure and function of the cytoskeleton in filamentous fungi
}

\author{
MARJATTA RAUDASKOSKI, VANAMO SALO and SARA S. NIINI
}

\begin{abstract}
RAUDASKOSKI, M., SALO, V. \& NIINI, S.S. 1988: Structure and function of the cytoskeleton in filamentous fungi. - Karstenia 28:49-60.

The application of immunocytochemical and immunobiochemical research methods to fungi has showed that microtubules and microfilaments are common structural components in the hyphae. In eukaryotic organisms other than fungi, microtubules and microfilaments are known to be involved in a variety of motile intracellular processes, such as directed movement of cell organelles, and in mitosis. In long fungal cells with apical extension, the microtubules and microfilaments may serve as pathways and guiding elements for the movement of nuclei and mitochondria towards the apex and also for transport of material from the site of synthesis to the site of secretion at the hyphal apex. The cytoskeletal elements, especially microtubules, may also play an integral role in the reciprocal exchange and migration of nuclei associated with the sexual reproduction in higher fungi. Unlike other cell organelles, microtubules and microfilaments respond to extra- and intracellular changes by assembly and disassembly cycles, which may be reflected in the growth and morphology of the hyphae. This makes microtubules and microfilaments attractive candidates through which the regulation of growth and morphogenesis in fungal hyphae may take place.
\end{abstract}

Marjatta Raudaskoski, Vanamo Salo \& Sara S. Niini, Department of Botany, University of Helsinki, Unioninkatu 44, SF-00170 Helsinki, Finland

\section{Abbreviations:}

\begin{tabular}{|c|c|}
\hline ATP & $=$ Adenosine triphosphate \\
\hline DAPI & $=4$,6-Diamidino-2-phenylindole \\
\hline FITCH & = Fluorescein isothiocyanate \\
\hline GTP & $=$ Guanosine triphosphate \\
\hline IIF & $=$ Indirect immunofluorescence \\
\hline kD & $=$ Kilodalton \\
\hline NBD & = 7-Nitrobenz-2-oxa-1,3-diazole \\
\hline PBS & $=$ Phosphate-buffered saline \\
\hline SDS-PAGE & $\begin{aligned}= & \text { Sodium dodecyl sulphate polyacrylamide-gel } \\
& \text { electrophoresis }\end{aligned}$ \\
\hline
\end{tabular}

The cytoskeleton in eukaryotic organisms comprises of microtubules, microfilaments and intermediate filaments. In fungal hyphae microtubules and microfilaments are common structural components but as yet no intermediate filaments have been detected (cf. McKerracher \& Heath 1987). Microtubules are composed of the specific proteins $\alpha$ - and $\beta$-tubulin and microfilaments of globular actin (G-actin) (Fig. 1) with molecular weights of $52-55 \mathrm{kD}$ and $42 \mathrm{kD}$, respectively. The $\alpha$ - and $\beta$-subunits combine to form heterodimers which further polymerize into microtubules (Fig. 1) with a diameter of $25 \mathrm{~nm}$ and varying lengths. The globular actin subunits also polymerize to form filamentous actin, two such filaments twist around each other (Fig. 1) and form the $7 \mathrm{~nm}$ microfilaments which are also distinguishable in ultrastructural studies. For the polymerization of microtubules (Mandelkow et al. 1987) and microfilaments (Korn 1987) GTP and ATP are respectively required. Both microtubules and microfilaments are labile structures which readily depolymerize and repolymerize, depending on the metabolic constituents of the cytoplasm, such as $\mathrm{Ca}^{2+}$-concentration (Hinssen 1987, Yin 1988). A large number of proteins have been identified in association with microtubules and microfilaments which are involved in regulation of polymerization and depolymerization of cytoskeletal elements, their association with other cell organelles 

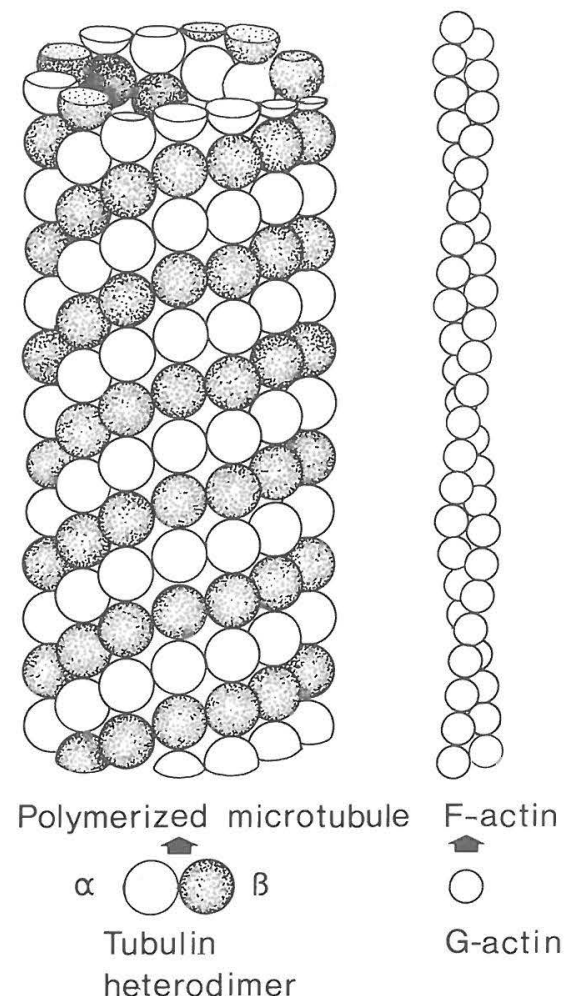

Fig. 1. Diagrammatic representation of the structure of a microtubule and microfilaments and their subunits. $\alpha$-(white ring) and $\beta$-(dotted ring) tubulin subunits join to $\alpha, \beta$-heterodimers, which polymerize to microtubules. G(globular)-actin polymerizes to $\mathrm{F}$ (filamentous)-actin. and the functioning of the cytoskeleton (Birchmeier 1984, Cassimeris et al. 1988). Of these proteins only myosin has been found in fungi (Watts et al. 1985), probably due to the recent application of immunocytochemical and -biochemical research methods in the study of the fungal cytoskeleton.

\section{Immunological investigations of the fun- gal cytoskeleton}

Earlier the only method available to study the fungal cytoskeleton was electron microscopy (Fig. 6). The application of indirect immunofluorescence (IIF) microscopy (Table 1A) to the study of the intact fungal cells started with the work by Kilmartin and Adams (1984) in which microtubules and microfilaments were visualized in yeast cells by using antibodies raised against yeast tubulin and actin. Their work was followed by IIF investigations which studied the distribution of microtubules in germlings of the rust Uromyces phaseoli (Hoch \& Staples 1985), in the hyphae of the filamentous fungus Schizophyllum commune (Runeberg et al. 1986), during the growth and division of the fission yeast Schizosaccharomyces pombe (Marks et al. 1986) and during zygote formation in the yeast Saccharomyces cerevisiae (Hašek et al. 1987). All these studies were possible with the aid of digestive enzymes that made the fungal cell wall permeable to antibodies after fixation. Study of the cytoskeleton in $S$. commune (Runeberg et al. 1986) also indicated that antibodies

Table 1. Procedures used in preparing the fungal hyphae for indirect immunofluorescence microscopy (IIF) and NBD-staining.

A. IIF procedure

- formaldehyde fixation

- enzymatic removal of cell walls

- treatment of the plasma membrane with Triton- $\mathrm{X}$ to increase membrane permeability

- treatment with the primary antibody (monoclonal $\alpha$ - or $\beta$-tubulin and actin antibodies)

- several washes with PBS

- treatment with the FITC- or rhodamine-conjugated secondary antibody

- mounting in glycerol: PBS $(1: 1)$ containing DAPI for DNA staining

B. NDB-phallacidin staining

- formaldehyde fixation

- enzymatic removal of cell walls (appears to be necessary in Schizophyllum and related fungi)

- mounting in buffer containing $0.8 \mu \mathrm{M}$ phallacidin (F-actin) 
raised against animal tubulins and actin were able to interact with the microtubules and microfilaments in fungal cells.

The method of visualizing actin filaments with fluorochrome-conjugated phalloin, phalloidin or phallacidin has also been applied to fungi (Hoch \& Staples 1983, Kilmartin \& Adams 1984, Runeberg et al. 1986, Marks et al. 1986, Hašek et al. 1987, Heath 1987). These compounds are mycotoxins produced by the poisonous mushroom Amanita phalloides. Phallotoxins (Wulf et al. 1979, Barak et al. 1980) bind specifically to filamentous actin further stabilizing the filaments and accelerating the polymerization of monomeric actin to filamentous actin (Wendel \& Dancker 1987). In most fungi the visualization of actin filaments with rhodamine-conjugated phalloin, phalloidin or NBD-phallacidin (Hoch \& Staples 1983, Kilmartin \& Adams 1984, Heath 1987) has been possible without cell wall digestion but in the hyphae of $S$. commune (Runeberg et al. 1986, Fig. 5a), Paxillus involutus (Fig. 5b) and Suillus bovinus (Fig. 5c) visualization of actin filaments with NBD-phallacidin has yet not been successful without the prior digestive treatment (Table 1B).

The antibodies raised against tubulins and actin can also be used in biochemical studies of cytoskeletal proteins by immunoblotting or Western blotting. For this purpose total proteins are extracted and analyzed by SDS-PAGE electrophoresis (Laemmli 1970) and the resulting polypeptides are transferred electrophoretically to nitrocellulose filter placed over the gel surface. After the transfer the filter is cut into strips according to the lanes of polypeptides. Treatment of each strip with a primary antibody raised against tubulins or actin followed by a peroxidase conjugated secondary antibody which interacts with the primary antibody enables the final visualization of the cytoskeletal protein through a peroxidase reaction (Towbin et al. 1979). This develops a coloured band at the position where the tubulin or actin is located among all the other polypeptides in the lane (Fig. 2). The molecular weight of the examined polypeptide is calculated with the help of polypeptide standards. Immunoblotting reliably indicates whether the antibody is able to interact with the antigen under investigation and also confirms the specificity of the antibody which is sometimes difficult on the basis of IIF microscopy alone. Occasionally several isotypes of $\alpha$ an B-tubulin or actin can be detected (Burland et al. 1983, Gull et al. 1986, Morris 1986) after further analysis of the polypeptides by two dimensional electrophoresis followed by immunoblotting.

Distribution of the cytoskeleton in fungal cells

The IIF microscopy has revealed a much more extensive cytoskeleton in fungal cells than it could be concluded from ultrastructural studies (Fig. 6). The tubulin antibodies visualize microtubules both in the apical and subapical hyphal cells of the homobasidiomycetes Schizophyllum commune, Suillus bovinus, Paxillus involutus, Amanita muscaria, A. regalis and also in the hyphae of the ascomycete Gyromitra esculenta (Figs. 3, 4). Of these fungi $S$. commune is
A

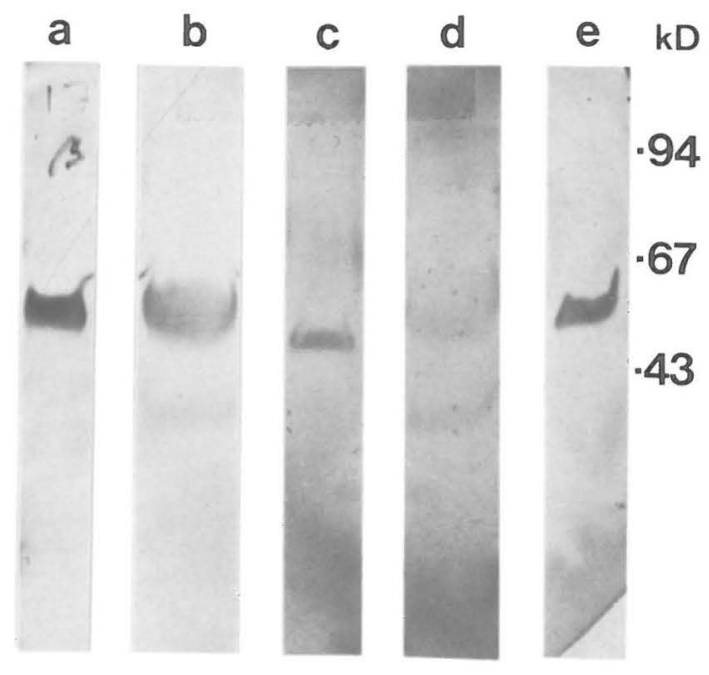

B

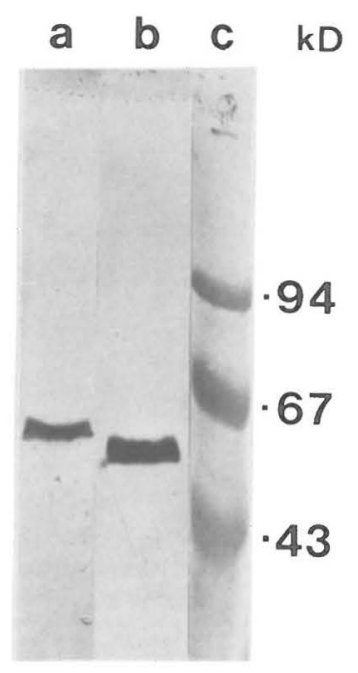

Fig. 2. - A: Immunoblot of A. B-tubulin of a) Suillus bovinus, b) Paxillus involutus, c) Gyromitra esculenta, d) Amanita muscaria and e) Schizophyllum commune. - B: Comparison of the structure of tubulins of Suillus bovinus a) $\alpha$ - and b) B-tubulin, c) molecular weight markers stained with amido black, $\mathrm{kD}=$ kilodaltons. 

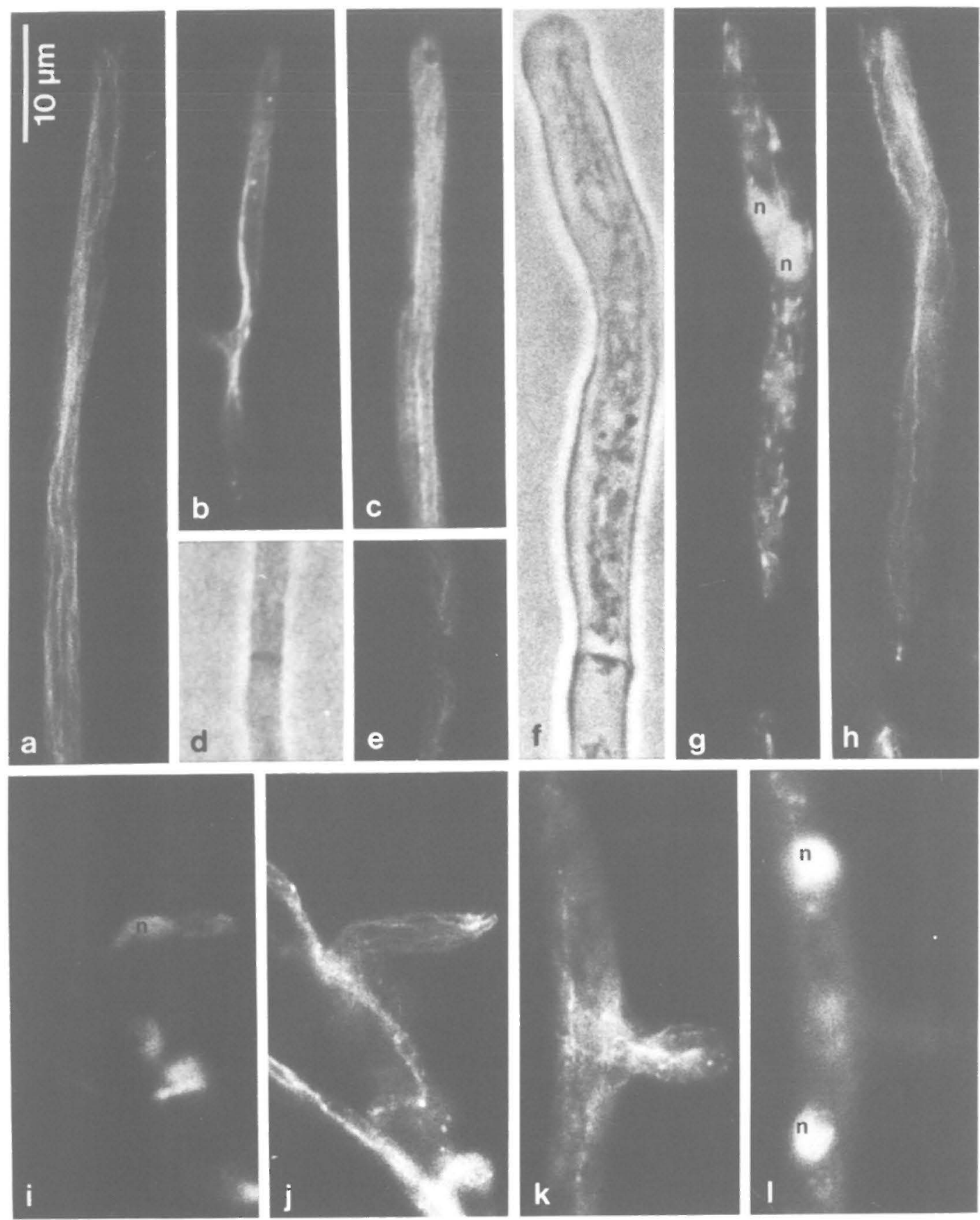

Fig. 3. Immunofluorescence of microtubules, DAPI-staining of nuclei and phase contrast microscopy of hyphae. Apical cells of a) Schizophyllum commune, b) Suillus bovinus and c) Paxillus involutus with longitudinal tracks of microtubules. Note the termination of microtubules slightly before the apex. d) A cross wall in a hypha of $S$. commune and e) the immunofluorescence microscopy shows termination of the microtubules at each side of the cross wall. - $\mathrm{f}-\mathrm{h}$ ) Apical cell of Gyromitra esculenta. $\mathrm{f}$ ) Phase contrast microscopy, g) DAPI-staining of nuclei (n) and rod-like mitochondria, h) immunofluorescence of microtubules, which terminate at the cross wall. - i, j) Hyphae of Amanita muscaria i) DAPI-staining of nuclei (n) and j) immunofluorescence 

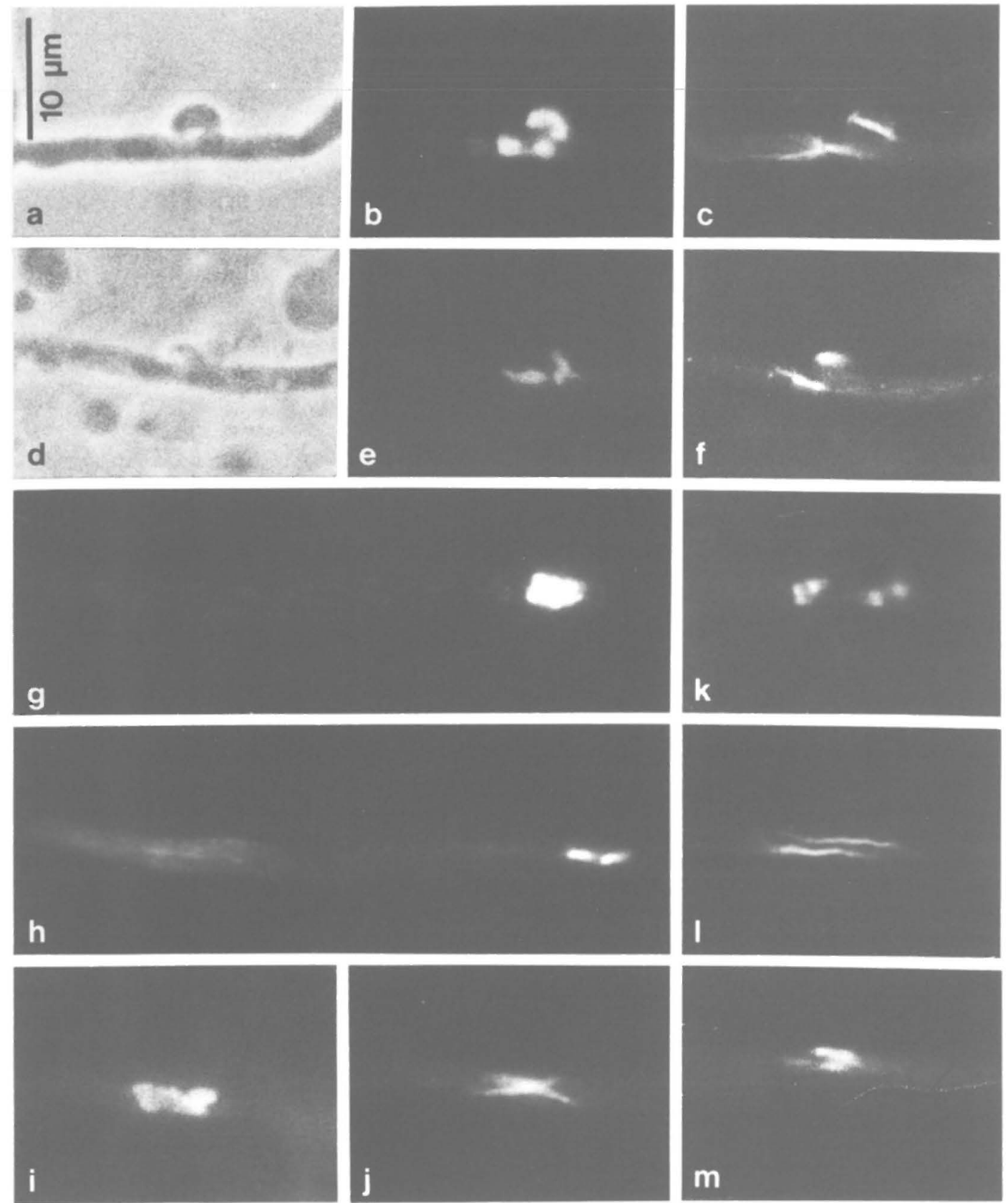

Fig. 4. Conjugate division. a-c. Schizophyllum commune and d-f. Paxillus involutus. - a, d) Phase contrast microscopy of a developing clamp connection, b, e) DAPI-staining of the nuclei and c, f) immunofluorescence of the spindles at anaphase in the same hyphae. - g-1) Conjugate division of nuclei of Amanita regalis described by DAPI-staining and indirect immunofluorescence microscopy of the same nuclei. g) DAPI-staining of DNA and h) immunofluorescence of the spindle of the same nuclei at metaphase. $i, k$ ) DAPI-staining of DNA and $j, 1$ ) immunofluorescence of spindles of the same nuclei at anaphase. Note the different orientation of spindles in $\mathrm{j}$ and $1 . \mathrm{m}$ ) The spindles of nuclei at anaphase in Suillus bovinus.

Fig. 3 (cont.) of microtubules in a branch. - k, 1) Branching in G. esculenta, k) immunofluorescence of microtubules and l) DAPIstaining of nuclei (n). 
a saprophytic fungus and $S$. bovinus, $P$. involutus, A. muscaria and A. regalis are mycorrhizal fungi (Niini \& Raudaskoski, in preparation). The ascomycete $G$. esculenta has been suspected to be mycorrhizal, although no experimental proof exists. In all these species microtubules extend from the apex to the cross wall in the apical cell and from the cross wall to next one in the subapical cell (Fig. 3d-f, h). The microtubules in the hyphae of the mycorrhizal species are often more relaxed and diffuse (Fig. 3b, c) than in the hyphae of S. commune (Fig. 3a) and occasionally only bright spots are detected instead of microtubules (Fig. 3b, j). However, comparable microtubule fluorescence to that in the hyphae of $S$. commune can be obtained in the mycorrhizal fungi when growth is good which suggests that the occasional poor fluorescence of microtubules could reflect poor metabolic activity in the hyphae.

Simultaneous division of two closely located nuclei in the mycelium of $S$. commune, $P$. involutus, $A$. regalis and $S$. bovinus can be recognized on the basis of the strong fluorescence of the two spindles at metaphase and anaphase (Fig. 4, see also Runeberg et al. 1986). From this it can be concluded that the mycelia of the mycorrhizal species are dikaryotic, as was to be expected, since in all the species presented it originated from fruit bodies. In S. commune (Fig. 4a-c) and in $P$. involutus (Fig. 4d-f), the division of the nuclei takes place in association with the development of a clamp connection, while in A. regalis (Fig. $4 \mathrm{~g}-\mathrm{l}$ ) and $S$. bovinus (Fig. $4 \mathrm{~m}$ ) no development of clamp connections occurs. This provides an opportunity to compare conjugate division in mycelia with and without clamp connections. In $A$. regalis and $S$. bovinus the two nuclei of the cell divide close to each other, despite the lack of development of a clamp connection. This can be seen from the location of spindles which either parallel each other (Fig. 41, m) or overlap (Fig. 4j). These observations indicate that the development of a clamp connection does not regulate the association or synchrony of the division of the nuclei in dikaryotic hyphae as could be concluded from conjugate division studies in hyphae with clamp connections. It is likely that the existence of yet unknown factors control the synchrony of division and maintain the association of the two nuclei of the hyphal cell in interphase. The latter idea is suggested by the close location of the nuclei in dikaryotic cells, irrespective of whether the hyphae have clamp connections or not.

Very similar spindle development occurs in hyphae with and without clamp connections. At metaphase the spindles are small rods with strong fluorescence (Fig. 4h, Runeberg et al. 1986) and from metaphase to anaphase the spindles may rotate slightly and are greatly elongated (Fig. 4c, f, j, l, m, Runeberg et al. 1986). A typical feature of late anaphase is the astral rays which extend from the spindle pole bodies deep into the cytoplasm (Fig. 4c, 1). At telophase the fluorescence of the spindles disappears, due to depolymerization of the spindle microtubules and in consequence the pole bodies with astral rays rotate slightly to the side of the nuclei. In the hyphae without clamp connections, the separation of the four nuclei, two in the apical and two in the subapical part of the cell, takes place almost synchronously. The microtubules still attached to the spindle pole bodies at the side of the nuclei appear to direct the separation and perhaps also ensure that the two nuclei in each cell stay close to each other during interphase. In the fungi in which nuclear division is connected with the formation of a clamp connection, one of the four nuclei is trapped in the clamp connection until the tip of the connection fuses with the subapical cell. The mechanism of the nuclear movement from the clamp connection into the subapical cell is not yet known, but it seems that microtubules may be involved, since they surround the nucleus in the clamp connection before fusion (Runeberg et al. 1986). This indicates that microtubules are available for the movement when the opening has formed from the clamp connection to the subapical cell. In spite of the excellent growth of the hyphae of G. esculenta in culture, and good visualization of their cytoplasmic microtubules by IIF and nuclei by DAPI staining (Fig. 3g, h, k, l), it has not yet been possible to detect the division of the nuclei by IIF microscopy for reasons not understood.

Treatment of the hyphae of $A$. muscaria, $P$. involutus, $S$. commune, and $S$. bovinus with NBDphallacidin (Fig. 5a-c) or actin antibodies (Fig. 5d, e) leads to the visualization of dots of actin in the apexes of the hyphae. Actin has also earlier been shown to be present in the homo- and dikaryotic hyphae of $S$. commune at the early stage of septum formation (Runeberg et al. 1986). It has not yet been possible to demonstrate the presence of actin in the hyphae of the ascomycete $G$. esculenta with either NBD-phallacidin or actin antibodies. Dots of actin with a distribution comparable to that in the apical cells of the homobasidiomycetes were revealed in the fission yeast Schizosaccharomyces pombe during different phases of the cell cycle (Marks et al. 1986). Dots and also thin filaments of actin were reported in the germlings of the rust Uromyces phaseoli (Hoch and Staples 1983, 1985). During zygote formation in the yeast Saccharomyces cerevisiae (Hašek et al. 1987) and in the hyphae of the oomycete Saprolegnia ferax (Heath 1987), long and conspicuous actin filaments were shown instead of dots. Whether the dots 

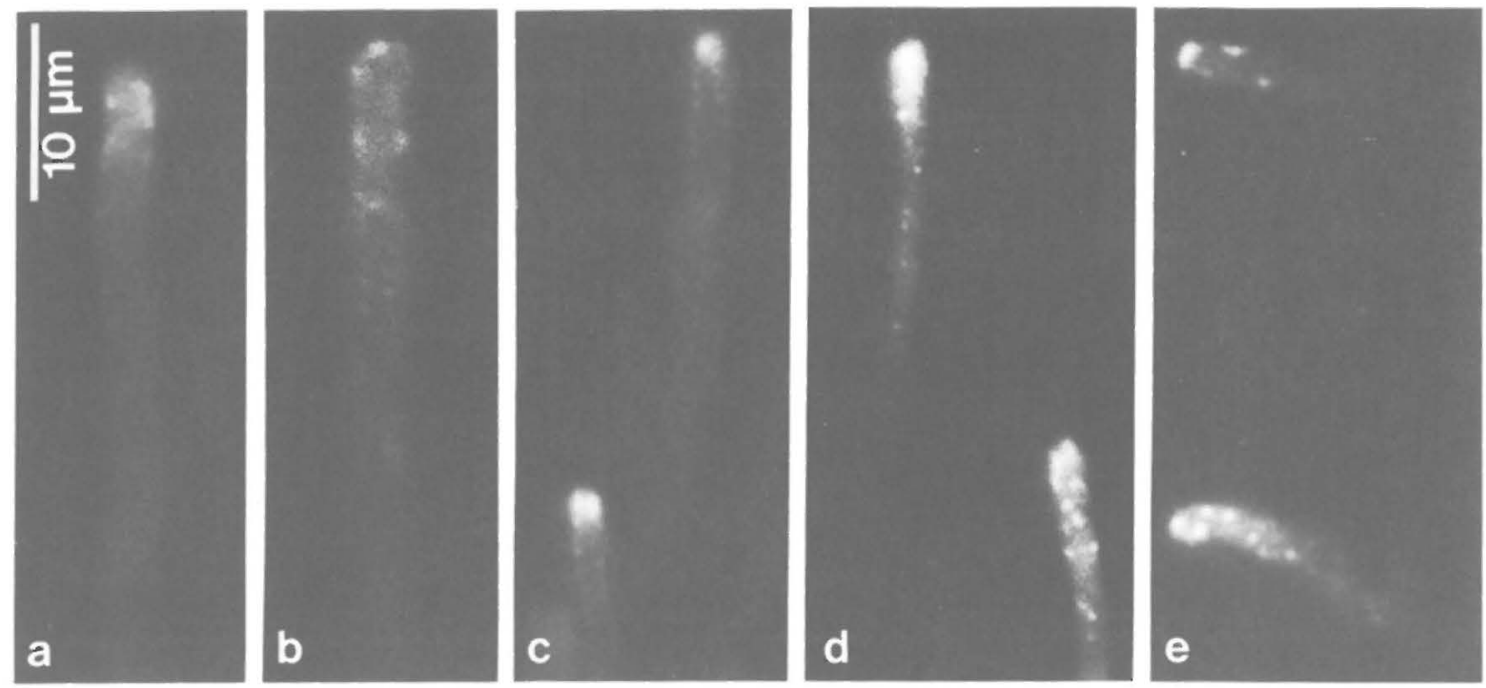

Fig. 5. NBD-phallacidin staining (a-c) and indirect immunofluorescence microscopy (d, e) of actin in the apical cells (a-d) and branches (e) of a) Schizophyllum commune, b, d) Paxillus involutus and c, e) Suillus bovinus.

represent the true structure of actin in the hyphae of the homobasidiomycetes (Fig. 5) or result from deficiency in experimental procedure that causes the break-down of actin filaments has to be resolved. It is noteworthy that dots of actin occur both when the hyphae are treated with NBD-phallacidin and when actin antibodies are used. This suggests that attention should be paid to the first steps in the procedures (Table 1).

Actin filaments are known to be sensitive to the procedures used in preparation of hyphae for ultrastructural studies but despite this, some observations have been made of filamentous structures that could be actin. In the homobasidiomycetes Polyporus biennis (Patton \& Marchant 1978), Trametes versicolor (Girbardt 1979) and Laetisaria arvalis (Hoch \& Howard 1980), thin filaments were reported in association with the early development of the septum, and these have now been shown by NBD-phallacidin staining to be actin (Runeberg et al. 1986). Vesicles coated with thin filaments (filasomes) have been observed in L. arvalis (Howard 1981), and in the hyphae of $S$. commune groups of thin filaments have been shown in the cytoplasm beneath the cell wall (Raudaskoski 1970, Raudaskoski \& Koltin 1973, Raudaskoski \& Salonen 1984).

The function of microfilaments cytoplasmic microtubules in the hyphae

and

The hyphal apex is one of the most intriguing structures in fungi and several functions may be attributed to it. The apex is the point of the extension growth, where the synthesis of new cell wall and extension of plasma membrane take place (Wessels 1986). The apex appears to respond to a change in the environmental conditions by increased or decreased extension or by bending or branching (Raudaskoski \& Kaukonen 1978, Raudaskoski \& Viitanen 1982, Raudaskoski \& Salonen 1984). The hyphal apex is the first to explore the growth medium, through which it makes its passage by excreting extracellular enzymes to hydrolyze wood (Levy 1980), humus and other organic tissue and it may also be involved in the recognition processes in the host-parasite interactions (Staples \& Hoch 1987). Ultrastructural studies have revealed a large number of vesicles at the apex (Grove et al. 1970, Girbardt 1973, Howard \& Aist 1979, Howard 1981). The vesicles and their interaction with plasma membrane have been interpreted as part of the extension growth of the hypha (Gooday 1983) and also as a part of general secretory pathway (Wessels 1986). The demonstration of microfilaments at the hyphal apex by the application of NBD-phallacidin and IIF microscopy (Hoch \& Staples 1983, 1985, Runeberg et al. 1986, Heath 1987) justifies some speculations regarding the functions in which the microfilaments may be involved.

It can be speculated that the microfilaments interact to form a cytoskeleton which maintains the hyphal apex in a dome-shape beneath the newly synthesized unpolymerized soft wall (Wessels 1986). This suggestion obtains some support from the experiment by Tucker et al. (1986) in which the depolymerization of 

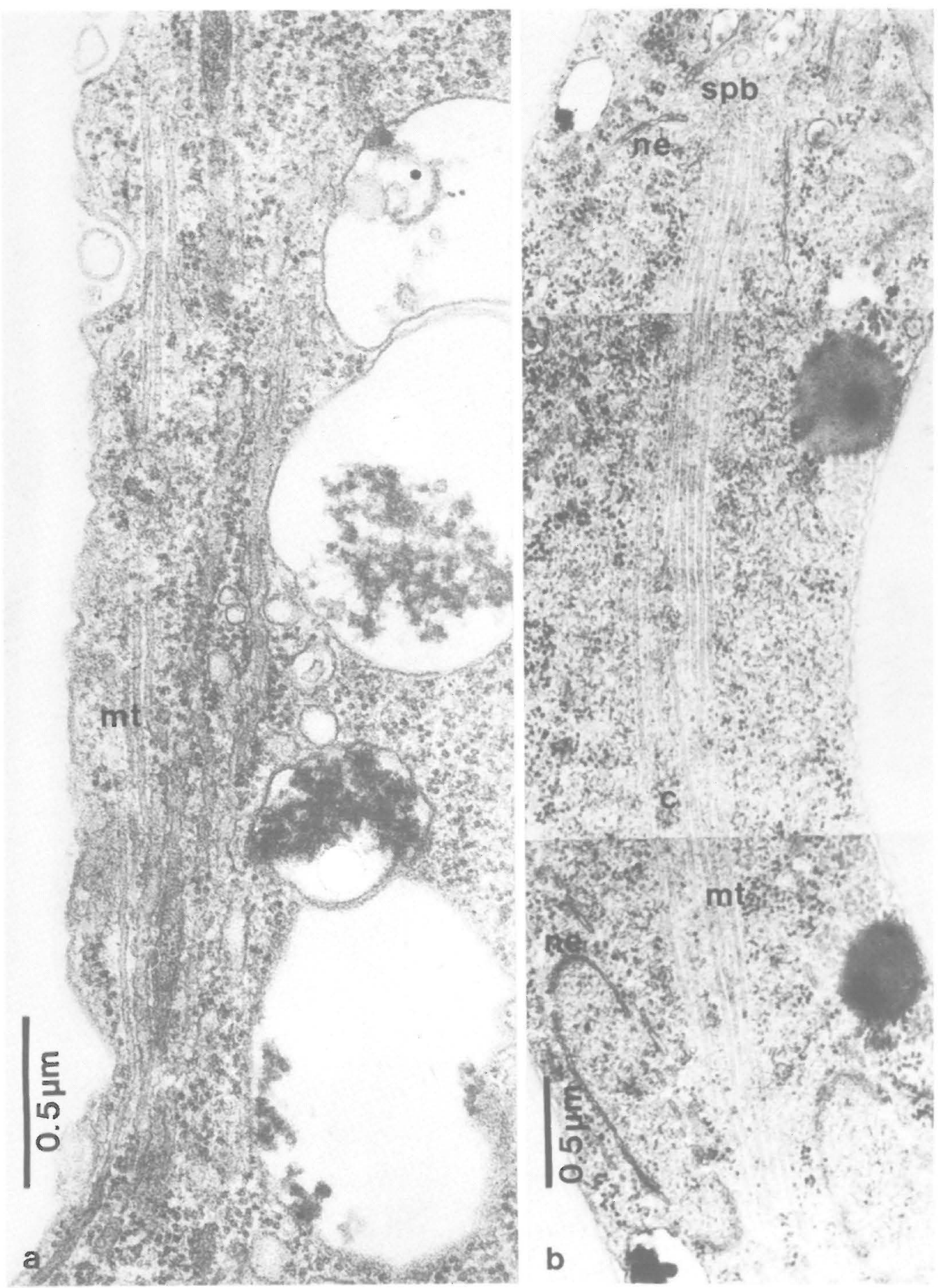

Fig. 6. Ultrastructure of microtubules in Schizophyllum commune. a) Cytoplasmic microtubules close to the cell wall, compare with Fig. 3. b) Spindle microtubules at anaphase, compare with Fig. 4. $\mathrm{c}=$ chromatin, $\mathrm{mt}=$ microtubules, ne = nuclear envelope, $\mathrm{spb}=$ spindle pole body. 
the microfilaments with cytochalasin E led to swelling of the hyphal tip while the removal of the drug caused the microfilaments to reassemble and the normal shape of the apex to reappear. The microfilaments at the apex could also be needed to direct the components necessary for wall synthesis to the appropriate locations enabling the symmetrical extension of the apex to be maintained. The involvement of microfilaments in wall synthesis is supported by the occurrence of filamentous actin at the anticipated site of deposition of the septum during cytokinesis (Girbardt 1979, Hoch \& Howard 1980, Runeberg et al. 1986). When the microfilaments protrude deep into the cytoplasm, as in the hyphae of $S$. ferax (Heath 1987), they could be involved in the long-distance membrane traffic necessary for exocytosis at the hyphal apex.

In eukaryotic cells other than fungi, cytoplasmic microtubules have been shown to participate in the positioning and transport of nuclei, mitochondria, chloroplasts and vesicles (Schnepf \& Quader 1987, Weiss 1987). In animal cells, the movement of mitochondria and vesicles along the microtubules has been studied extensively in the long axons of nerve cells (Weiss 1987) and in the large reticulate, multinucleate protozoan Reticulomyxa (Schliwa et al. 1987) by video-enhanced light microscopy (cf. Shotton 1988). The biochemical analyses combined with this method have indicated novel proteins, which are able to mediate the association between the cell organelles and microtubules and which in the presence of ATP move the organelles either forwards (Weiss 1987, Scheetz 1988) or backwards (Paschal \& Vallee 1987) along the microtubules. An attractive idea is that the longitudinally orientated microtubule tracks distinguished with IIF microscopy in fungal hyphae are also involved in the transport of cell organelles towards the apex, especially in the apical cells, which may extend for several hundreds of micrometers. It is well established that in the apical cells of the monoand dikaryotic hyphae of $S$. commune the nucleus/ nuclei move forward in concert with the apical extension (Snider 1968, Niederpruem et al. 1971), but the microtubules could also serve as guide lines for the transport of vesicles necessary for the growth of the apex from the site of synthesis to the site of secretion. This function was also suggested above for the microfilaments in the hyphae of the oomycete $S$. ferax.

For the design of experiments intended to clarify the functions of different cytoskeletal components in the fungal hyphae, it is important to resolve the actual distribution of microtubules and microfilaments in the hyphae of the higher fungi. If the distribution of microfilaments and microtubules is indeed like that de- scribed earlier (Runeberg et al. 1986) and at present in the hyphae of $S$. commune and now also observed in the hyphae of the mycorrhizal fungi, then the transport of cell organelles towards the apex could be associated with microtubules. If the present view of the distribution of microfilaments in the hyphae of higher fungi is too restricted, the distribution being more like that described in the oomycete $S$. ferax (Heath 1987) and rust $U$. phaseoli (Hoch \& Staples 1983), then it is possible to speculate that different cell organelles may be able to interact with different cytoskeletal components or that both the microtubules and microfilaments may be simultaneously involved in the positioning and transport of cell organelles. The latter interpretation seems to be true in plant cells in which microtubules and microfilaments are shown to run parallel and in close association in the cortical part of the cytoplasm (Raudaskoski et al. 1987, Noguchi \& Ueda 1988), and to be simultaneously associated with mitochondria (Raudaskoski et al. 1987) or chloroplasts (Menzel \& Schliwa 1986).

\section{Cytoskeletal elements associated with intercellular nuclear migration}

In the homobasidiomycetes the reciprocal exchange and migration of nuclei between compatible haploid strains leads to the dikaryotization of both strains. The phenomenon is a part of the sexual reproduction of the higher fungi and is under control of incompatibility genes (Raper 1966). Prerequisites for intercellular nuclear migration are hyphal fusions between the haploid mycelia and break-down of cross walls (Giesy \& Day 1965, Raudaskoski 1972a, b, 1973, Raudaskoski \& Koltin 1973, Niederpruem 1980, Korhonen 1983). The efficiency of intercellular nuclear migration varies between different fungal species. In Coprinus congregatus the nuclei were calculated to migrate at a rate of $4 \mathrm{~cm} \mathrm{~h}^{-1}$ (Ross 1976), in compatible matings of Armillaria the maximum recorded velocity was $170 \mu \mathrm{m} \mathrm{h}^{-1}$ (Korhonen 1983), while during intercellular nuclear migration in $S$. commune three different categories of migration were observed, with maximum rates of $81 \mu \mathrm{m}, 236 \mu \mathrm{m}$ and $2000 \mu \mathrm{m} \mathrm{h}^{-1}$ (Niederpruem 1980). The occurrence of reciprocal exchange of nuclei between compatible strains of ectomycorrhizal homobasidiomycetes may also be deduced from the dikaryotization of mated haploid mycelia of Hebeloma cylindrosporum (Debaud et al. 1986).

The ultrastructural and IIF studies in S. commune suggest that microtubules play an integral role in intercellular nuclear migration. The microtubule tracks continue through hyphal fusions (Raudaskoski et al. 
1988) and dissolved septa (Raudaskoski \& Koltin 1973) and in nuclei occurring in association with the tracks, the envelope appears to be stretched parallel to the microtubule bundles (Raudaskoski 1984). The number of nuclear divisions also increases during intercellular nuclear migration (Raudaskoski 1973, Korhonen 1983, Raudaskoski et al. 1988). These observations together with the records of nuclear movements in living hyphae (Niederpruem 1980) suggest that several mechanisms may be responsible for nuclear migration. The reciprocal exchange and migration of nuclei between compatible haploid strains could involve telophase movement of the nuclei, which, due to the absence of cross walls in the migration hyphae, could result in the sister nuclei being farther apart after the division than in the apical cell. During telophase the astral microtubules associated with the spindle pole bodies are involved (Runeberg et al. 1986). The interphase nuclei also appear to participate in the migration (Niederpruem 1980, Raudaskoski 1984). In this case the microtubule tracks running through the anastomoses and broken septa could serve as guide lines for some force-generating system associated with the nuclear envelope. The connection of microfilaments with intercellular nuclear migration is completely unknown, though microfilament-like structures have been described in migration hyphae (Raudaskoski \& Koltin 1973).

\section{Special functions of cytoskeleton in my- corrhizal fungi}

The strong branching of hyphae of Hebeloma cylindrosporum after contact with the root hairs of the host Picea mariana (Massicotte et al. 1987), together with the occurrence of microtubules and microfilaments in the hyphal branches of mycorrhizal fungi (Figs. 3j, 5e), suggests that attention should be paid to the role of the cytoskeleton in the establishment of the fungus-root association. In plant-pathogenic fungi, recent studies have indicated that cytoskeletal elements may be necessary for the orientated growth of the germlings of the rust fungus Uromyces appendiculatus on the leaf surface of the host and for the differentiation of the first infection structure the appressorium (Staples \& Hoch 1987, Hoch et al. 1987a, b, Tucker et al. 1986, Bourett et al. 1987).

Among the translocation processes associated with the mycorrhiza, that most frequently studied is the translocation of phosphorus from the soil to the host. In the endomycorrhizal fungi with non-septate hyphae, cytoplasmic streaming is suspected to be re- sponsible for transport of vacuoles containing polyphosphate granules (Gianinazzi-Pearson \& Gianinazzi 1986). In septate ascomycetes and basidiomycetes, phosphorus has been shown to move through strands formed by longitudinal aggregation of hyphae (Finlay \& Read 1986). The main power for the flux of phosphorus through the strands is suggested to be the symplastic flow. The occurrence of microtubules and microfilaments in the hyphae of fungi which are able to establish a mycorrhizal symbiosis highlights the possibility that cytoskeletal elements may be involved in translocation processes specific for the mycorrhizal fungi.

\section{References}

Barak, L.S., Yocum, R.R., Nothnagel, E.A. \& Webb, W.W. 1980: Fluorescence staining of the actin cytoskeleton in living cells with 7-nitrobenz-2-oxa-1,3diazole-phallacidin. - Proc. Natl. Acad. Sci. USA 77: 980-984.

Birchmeier, W. 1984: Cytoskeleton structure and function. — Trends Biochem. Sci. 9:192-195.

Bourett, T., Hoch, H.C. \& Staples, R.C. 1987: Association of the microtubule cytoskeleton with the thigmotropic signal for appressorium formation in Uromyces. - Mycologia 79:540-549.

Burland, T.G., Gull, K., Schedl, T., Boston, R.S. \& Dove, W.F. 1983: Cell type-dependent expression of tubulins in Physarum. - J. Cell Biol. 97:1852-1859.

Cassimeris, L.U., Walker, R.A., Pryer, N.K. \& Salmon, E.D. 1988: Dynamic instability of microtubules. - BioEssays 7:149-154.

Debaud, J.C., Gay, G. \& Bruchet, G. 1986: Intraspecific variability in an ectomycorrhizal fungus: Hebeloma cylindrosporum. 1. Preliminary studies on in vitro fruiting, spore germination and sexual comportment. In: Gianinazzi-Pearson, V. \& Gianinazzi, S. (eds.), Physiological and genetical aspects of mycorrhizae. Proceedings 1st Europ. Symp. Mycorrhizae: 581-588. INRA, Paris.

Finlay, R.D. \& Read, D.J. 1986: The uptake and distribution of phosphorus by ectomycorrhizal mycelium. In: Gianinazzi-Pearson, V. \& Gianinazzi, S. (eds.), Physiological and genetical aspects of mycorrhizae. Proceedings 1st Europ. Symp. Mycorrhizae: 351-355. INRA, Paris.

Gianinazzi-Pearson, V. \& Gianinazzi, S. 1986: The physiology of improved phosphate nutrition in mycorrhizal plants. - In: Gianinazzi-Pearson, V. \& Gianinazzi, S. (eds.), Physiological and genetical aspects of mycorrhizae. Proceedings 1st Europ. Symp. Mycorrhizae: 101109. INRA, Paris.

Giesy, R.M. \& Day, P.R. 1965: The septal pores of Coprinus lagopus in relation to nuclear migration. Amer. J. Bot. 52:287-293.

Girbardt, M. 1973: Die Pilzzelle. - In: Hirsch, G.C., Ruska, H. \& Sitte, P. (eds.), Grundlagen der Cytologie: 441-460. Fischer, Jena.

- 1979: A microfilamentous septal belt (FSB) during induction of cytokinesis in Trametes versicolor (L. ex Fr.). Exp. Mycol. 3:215-228.

Gooday, G.W. 1983: The hyphal tip. - In: Smith, J.E. (ed.), Fungal differentiation. A contemporary synthesis. 
Lemke, P.A. (ed.), Mycology Series 4: 315-356. Marcel Dekker, Inc., New York and Basel.

Grove, S.N., Bracker, C.E. \& Morré, D.J. 1970: An ultrastructural basis for hyphal tip growth in Pythium ultimum. - Amer. J. Bot. 57:245-266.

Gull, K., Hussey, P.J., Sasse, R., Schneider, A., Seebeck, T. \& Sherwin, T. 1986: Tubulin isotypes: Generation of diversity in cells and microtubular organelles. - J. Cell. Sci. Suppl. 5:243-255.

Hašek, J., Rupes, I., Svobodová, J. \& Streiblová, E. 1987: Tubulin and actin topology during zygote formation of Saccharomyces cerevisiae. - J. Gen. Microbiol. 133:3355-3363.

Heath, I.B. 1987: Preservation of a labile cortical array of actin filaments in growing hyphal tips of the fungus Saprolegnia ferax. - Eur. J. Cell Biol. 44:10-16.

Hinssen, H. 1987: Actin-modulating proteins. Complex formation and $\mathrm{Ca}^{++}$-dependence of interaction with actin. - In: Wohlfarth-Bottermann, K.E. (ed.), Nature and function of cytoskeletal proteins in motility and transport. Fortschritte der Zoologie 34:53-63. G. Fischer, Stuttgart \& New York

Hoch, H.C. \& Howard, R.J. 1980: Ultrastructure of freeze-substituted hyphae of the basidiomycete Laetisaria arvalis. - Protoplasma 103:281-297.

Hoch, H.C. \& Staples, R.C. 1983: Visualization of actin in situ by rhodamine-conjugated phalloin in the fungus Uromyces phaseoli. - Eur. J. Cell Biol. 32:52-58.

- 1985: The microtubule cytoskeleton in hyphae of Uromyces phaseoli germlings: Its relationship to the region of nucleation and to the F-actin cytoskeleton. - Protoplasma 124:112-122.

Hoch, H.C., Staples, R.C., Whitehead, B., Comeau, J. \& Wolf, E.D. 1987a: Signaling for growth orientation and cell differentiation by surface topography in Uromyces. - Science 235:1659-1662.

Hoch, H.C., Tucker, B.E. \& Staples, R.C. 1987b: An intact microtubule cytoskeleton is necessary for mediation of the signal for cell differentiation in Uromyces. Eur. J. Cell Biol. 45:209-218.

Howard, R.J. 1981: Ultrastructural analysis of hyphal tip cell growth in fungi: Spitzenkörper, cytoskeleton and endomembranes after freeze-substitution. - J. Cell Sci. 48:89-103.

Howard, R.J. \& Aist, J.R. 1979: Hyphal tip cell ultrastructure of the fungus Fusarium. Improved preservation by freeze-substitution. - J. Ultrastruc. Res. 66:224-234.

Kilmartin, J.V. \& Adams, A.E.M. 1984: Structural rearrangements of tubulin and actin during the cell cycle of the yeast Saccharomyces. - J. Cell Biol. 98:922-933.

Korhonen, K. 1983: Observations on nuclear migration and heterokaryotization in Armillaria. - Cryptog., Mycol. 4:79-85.

Korn, E.D. 1987: Regulation of actin polymerization by ATP hydrolysis and actin-binding proteins. In: WohlfarthBottermann, K.E. (ed.), Nature and function of cytoskeletal proteins in motility and transport. Fortschritte der Zoologie 34:65-76. G. Fischer, Stuttgart \& New York.

Laemmli, U.K. 1970: Cleavage of structural proteins during the assembly of the head of bacteriophage T4. - Nature 227:680-685

Levy, J.F. 1980: The place of basidiomycetes in the decay of wood in contact with the ground. In: Frankland, J.C., Hedger, J.N. \& Swift, M.J. (eds.), Decomposer basidiomycetes. Brit. Mycol. Soc. Symp. Series 4:161-178. Cambridge Univ. Press.
Mandelkow, E-M., Linse, K., Spann, U. \& Mandelkow, E. 1987: Domain structure, nucleotide-binding site, and assembly of tubulin. In: Wohlfarth-Bottermann, K.E. (ed.), Nature and function of cytoskeletal proteins in motility and transport. Fortschritte der Zoologie 34:125132. G. Fisher, Stuttgart \& New York.

Marks, J., Hagan, I.M. \& Hyams, J.S. 1986: Growth polarity and cytokinesis in fission yeast: the role of the cytoskeleton. - J. Cell Sci. Suppl. 5:229-241.

Massicotte, H.B., Melville, L.H. \& Peterson, R.L. 1987: Scanning electron microscopy of ectomycorrhizae, potential and limitations. - Scanning Microscopy 1:1439-1454.

McKerracher, L.J. \& Heath, I.B. 1987: Cytoplasmic migration and intracellular organelle movements during tip growth of fungal hyphae. - Exp. Mycol. 11:79-100.

Menzel, D. \& Schliwa, M. 1986: Motility in the siphonous green alga Bryopsis. II. Chloroplast movement requires organized arrays of both microtubules and actin filaments. - Eur. J. Cell Biol. 40:286-295.

Morris, N.R. 1986: The molecular genetics of microtubule proteins in fungi. - Exp. Mycol. 10:77-82.

Niederpruem, D.J. 1980: Direct studies of dikaryotization in Schizophyllum commune. I. Live inter-cellular nuclear migration patterns. - Arch. Microbiol. 128:162-171.

Niederpruem, D.J., Jersild, R.A. \& Lane, P.L. 1971: Direct microscopic studies of clamp connection formation in growing hyphae of Schizophyllum commune. I. The dikaryon. - Arch. Mikrobiol. 78:268-280.

Noguchi, T. \& Ueda, K. 1988: Cortical microtubules and cortical microfilaments in the green alga, Micrasterias pinnatifida. - Protoplasma 143:188-192.

Paschal, B.M. \& Vallee, R.B. 1987: Retrograde transport by the microtubule-associated protein MAP 1C. Nature 330:181-183.

Patton, A.M. \& Marchant, R. 1978: An ultrastructural study of septal development in hyphae of Polyporus biennis. - Arch. Microbiol. 118:271-277.

Raper, J.R. 1966: Genetics of sexuality in higher fungi. 283 pp. The Ronald Press Company. New York.

Raudaskoski, M. 1970: Occurrence of microtubules and microfilaments, and origin of septa in dikaryotic hyphae of Schizophyllum commune. - Protoplasma 70:415422.

- 1972a: Occurrence of microtubules in the hyphae of Schizophyllum commune during intercellular nuclear migration. - Arch. Mikrobiol, 86:91-100.

- 1972b: Secondary mutations at the BB incompatibility locus and nuclear migration in the basidiomycete Schizophyllum commune. - Hereditas 72:175-182.

- 1973: Light and electron microscope study of unilateral mating between a secondary mutant and a wild-type strain of Schizophyllum commune. - Protoplasma 76:35-48.

- 1984: Unusual structure of nuclei in a B-mutant strain of Schizophyllum commune with intercellular nuclear migration. - Nord. J. Bot. 4:217-233.

Raudaskoski, M. \& Kaukonen, P. 1978: Effects of hydroxyurea on development of uninucleate apical cells of Schizophyllum commune. - Exp. Mycol. 2:239-244.

Raudaskoski, M. \& Koltin, Y. 1973: Ultrastructural aspects of a mutant of Schizophyllum commune with continuous nuclear migration. - J. Bact. 116:981-988.

Raudaskoski, M. \& Salonen, M. 1984: Interrelationships between vegetative development and basidiocarp initiation. - In: Jennings, D.H. \& Rayner, A.D.M. (ed.), The ecology and physiology of the fungal mycelium. Brit. 
Mycol. Soc. Symp. Series 8:291-322. Cambridge Univ. Press.

Raudaskoski, M., Perttilä, K., Salo, V. \& Runeberg-Roos, P. 1988: Visualization of microtubules and characterization of tubulins of the filamentous fungus Schizophyllum commune. - Physiol. Plantarum 73:11A.

Raudaskoski, M. \& Viitanen, H. 1982: Effect of aeration and light on fruit body induction in Schizophyllum commune. - Trans. Br. mycol. Soc. 78:89-96.

Raudaskoski, M., Aström, H., Perttilä, K., Virtanen, I. \& Louhelainen, J. 1987: Role of the microtubule cytoskeleton in pollen tubes: an immunocytochemical and ultrastructural approach. - Biol. of the Cell 61:177-188

Ross, I.K. 1976: Nuclear migration rates in Coprinus congregatus: A new record? - Mycologia 68:418-422.

Runeberg, P., Raudaskoski, M. \& Virtanen, I. 1986: Cytoskeletal elements in the hyphae of the homobasidiomycete Schizophyllum commune visualized with indirect immunofluorescence and NBD-phallacidin. - Eur. J. Cell Biol. 41:25-32.

Schliwa, M., Euteneuer, U. \& Koonce, M.P. 1987: Identification of a protein involved in microtubule-dependent organelle movements of the giant amoeba, Reticulomyxa. - In: Wohlfarth-Bottermann, K.E. (ed.), Nature and function of cytoskeletal proteins in motility and transport. Fortschritte der Zoologie 34:156-169. G. Fischer, Stuttgart \& New York.

Schnepf, E. \& Quader, H. 1987: Functions of microtubules in plant cells. - In: Wohlfarth-Bottermann, K.E. (ed.), Nature and function of cytoskeletal proteins in motility and transport. Fortschritte der Zoologie 34:115124. G. Fischer, Stuttgart \& New York.

Sheetz, M.P. 1988: What are the functions of kinesin. BioEssays 7:165-168.

Shotton, D.M. 1988: Review: Video-enhanced light microscopy and its applications in cell biology. - J. Cell Sci. 89:129-150.

Snider, P.J. 1968: Nuclear movements in Schizophyllum. - In: Miller, P.L. (ed.), Aspects of cell motility. Symp Soc. Exp. Biol. 22:261-283. Cambridge Univ. Press.

Staples, R.C. \& Hoch, H.C. 1987: Infection structures - form and function. - Exp. Mycol. 11:163-169.

Towbin, H., Staehelin, T. \& Gordon, J. 1979: Electrophoretic transfer of proteins from polyacrylamide gels to nitrocellulose sheets: procedure and applications. Proc. Natl. Acad. Sci. USA 76:4350-4354.

Tucker, B.E., Hoch, H.C. \& Staples, R.C. 1986: The involvement of F-actin in Uromyces cell differentiation: The effects of cytochalasin $\mathrm{E}$ and phalloidin. Protoplasma 135:88-101.

Watts, F.Z., Miller, D.M. \& Orr, E. 1985: Identification of myosin heavy chain in Saccharomyces cerevisiae. - Nature 316:83-85.

Wendel, H. \& Dancker, P. 1987: Influence of phalloidin on both the nucleation and the elongation phase of actin polymerization. - Biochim. Biophys. Acta 915:199-204.

Weiss, D.G. 1987: Visualization of microtubule gliding and organelle transport along microtubules from squid giant axons. - In: Wohlfarth-Bottermann, K.E. (ed.), Nature and function of cytoskeletal proteins in motility and transport. Fortschritte der Zoologie 34:133-144.

Wessels, J.G.H. 1986: Cell wall synthesis in apical hyphal growth. - Intern. Rev. Cytol. 104:37-79.

Wulf, E., Deboben, A., Bautz, F.A., Faulstich, H. \& Wieland, Th. 1979: Fluorescent phallotoxin, a tool for the visualization of cellular actin. - Proc. Natl. Acad. Sci. USA 76:4498-4502.

Yin, H.L. 1988: Gelsolin: Calcium- and polyphosphoinositide-regulated actin-modulating protein. - BioEssays 7: 176-179.

Accepted for publication on 20 September 1988 